Southern Illinois University Carbondale

OpenSIUC

Working Papers

Political Networks Paper Archive

Summer 8-8-2010

\title{
Networking Networkers: An Initial Exploration of the Patterns of Collaboration among the Members of a New Community in Political Science
}

Ramiro Berardo

University of Arizona, berardo@email.arizona.edu

Follow this and additional works at: http://opensiuc.lib.siu.edu/pn_wp

\section{Recommended Citation}

Berardo, Ramiro, "Networking Networkers: An Initial Exploration of the Patterns of Collaboration among the Members of a New Community in Political Science" (2010). Working Papers. Paper 49.

http://opensiuc.lib.siu.edu/pn_wp/49

This Article is brought to you for free and open access by the Political Networks Paper Archive at OpenSIUC. It has been accepted for inclusion in Working Papers by an authorized administrator of OpenSIUC. For more information, please contact opensiuc@lib.siu.edu. 


\title{
Networking Networkers: An Initial Exploration of the Patterns of Collaboration among the Members of a New Community in Political Science ${ }^{1}$
}

\author{
Ramiro Berardo \\ University of Arizona \\ berardo@email.arizona.edu
}

\footnotetext{
${ }^{1}$ Ruth Alminas at the University of Arizona provided valuable research assistance during the first stage of this project. I thank Scott McClurg and Joe Young for their comments on a previous draft. I also thank James Fowler, David Lazer, Hans Noel, and John Scholz for comments that helped me improve the survey used to collect the data analyzed in this article. The usual caveats apply.
} 
There are a number of indicators that signal the growing interest on the study of political phenomena from a network perspective in the U.S. (the growing number of published articles with a network focus in the top-tier journals in the discipline, the creation of a new section of the American Political Science Association in 2008 with the name "Political Networks", etc.). One of these indicators is the creation of a new annual conference financially supported by the National Science Foundation (NSF-0851084, NSF-0757843) that brings together scholars who study networks in political science, but also fosters collaboration across disciplines by encouraging participation of non-political scientists with the goal of providing more comprehensive answers to questions that cannot be properly answered in the confines of individual disciplines.

So far the conference has taken place three times: in June of 2008 and 2009 at Harvard University, and in May of 2010 at Duke University. ${ }^{2}$ These annual meetings give scholars the opportunity to present research, and gain methodological training in workshops geared toward grad students and faculty. But perhaps more importantly, they provide a setting where professional collaboration may unfold among the members of this new scholarly community. In this article I examine how the conference is shaping this new community by showing: 1) who attended the first two conferences, 2) how they engaged in collaboration with other attendees, and 3) whether new collaborative links bridge the limits of particular disciplines and subfields in political science. This last issue is particularly important to explore because Political Science has been characterized repeatedly as a discipline where scholars tend to work in compartmentalized ways (Almond 1988), many times ignoring - for instance- the professional benefits that can be derived from collaborative exchanges across subfields (see, for example, Garand and Giles 2003) or disciplines. The emergence of collaborative links at the networks conferences connecting subfields of Political Science or bridging the void between our discipline and others would suggest that a rich scholarly network is

\footnotetext{
${ }^{2}$ A fourth conference is scheduled for 2011 at the University of Michigan.
} 
developing that should facilitate a more comprehensive study of politics; the end result should be an enhanced ability to understand how political processes work. ${ }^{3}$ The next section provides a short description of the process of data collection. A later section presents results in a two-fold manner; first, the patterns of collaboration and their changes are addressed; then, a homophily analysis shows the tendency of scholars that attended the conferences to diversify their contacts in a way that allows for professional collaboration across disciplines and subfields in Political Science.

\section{Data Collection}

In December of 2008 and October of 2009 I released two online surveys directed to the participants of the 2008 and 2009 Political Networks conferences respectively (both organized at Harvard University). In 2008, the survey was answered by 96 of the 147 individuals who attended the conference (response rate of 65.3\%). The second survey, released in 2009, was answered by 108 individuals out of the 139 who attended the conference (response rate of $77.7 \%$ ). Survey respondents provided information about the main discipline in which they were active, and in case that they identified themselves as political scientists, to identify the main subfield in which they worked. Of the 147 individuals who attended the 2008 conference, about 69\% (101/147) were political scientists. The subfield in the discipline with the largest representation was American Politics with 30 attendees ( $20 \%$ of the total), followed by Public Policy/Public Administration with $24(\sim 16 \%)$, and International Relations and Comparative Politics with 18 scholars each $(\sim 12 \%)$. A total of 9 other individuals did not fit in the categories provided above and were grouped as being active in "other subfield" (\%6), with the majority of them (6 out of 9$)$ identifying themselves as "political methodologists"4. Also in attendance were 42 scholars $(\sim 29 \%$ of the total) who were

\footnotetext{
${ }^{3}$ The analysis is performed only with data from the first two conferences. Data for 2010 had not yet been collected as of the writing of this article (March 2010).

${ }^{4}$ The first survey (released in 2008) included categories for Public Law, Political Theory, and Political Methodology that were collapsed for the analysis since the first two categories almost had no representation at the conference. The second survey presented the collapsed categories as "other
} 
active in a discipline other than Political Science. ${ }^{5}$ Sociologists formed the most important part of this group with 17 individuals ( $\sim 12 \%$ of the total number of participants). The remaining 25 nonpolitical scientists in attendance ( $\sim 17 \%$ of the total), came from disciplines like Philosophy, Statistics, and Economics, among others.

In 2009, the number of political scientists in attendance as a percentage of the total remained stable at about $67 \%(93 / 138)$. Also, the distribution by subfield was relatively stable when compared to 2008; American Politics is the subfield with the largest representation (28 scholars or 20\%), followed by Public Policy/Public Administration (21 scholars, 15\% of the total) and International Relations and Comparative Politics (15 attendees each, 11\%). However, the respondents picking the "other subfield" category grew in 2009 when compared to 2008 . A total of $15(\sim 11 \%)$ individuals picked this category, with the majority of them choosing "Political Methodology" as their main area of interest. Among non-political scientists, the distribution did see some more significant changes. The percentage of sociologists dropped to approximately $7 \%$ of the total $(10 / 139)$, whereas other non-political scientists became more important in 2009. There were 35 individuals, or over $25 \%$ of attendees who came from a variety of disciplines including Law, Computational Linguistics, Computer Science, Economics, Philosophy, Psychology, and Statistics; the second conference was more diverse than the first one in terms of represented disciplines.

The main goal of each of the two surveys was to map collaboration networks of among conference participants. To accomplish this goal, each respondent was presented with a list of all other attendees to the conference, preceded by the following statement: "Below is a list of

subfield" and allowed for write-ins so the respondents could clarify in which subfield they were more active. Both in 2008 and 2009, the majority of individuals in the "other subfield" category are methodologists.

${ }^{5}$ Data of individual attributes for non-respondents both in 2008 and 2009 were obtained with Google searches. I was not able to gather information of this type for a total of 4 individuals. 
individuals who attended the (2008 or 2009) Harvard Political Networks Conference. Please

indicate:

1. with whom you have collaborated in writing before attending the conference (articles, grant proposals, papers, etc.-include those in progress).

2. with whom you have collaborated in writing since attending the conference and as a result of such attendance (articles, grant proposals, papers, etc.).

3. with whom you have informally exchanged professional advice before the conference, and

4. with whom you have informally exchanged professional advice since attending the conference and as a result of such attendance."

With the answers, I created squared directed matrices for 2008 and 2009 that included only respondents to the survey. Since these links are obviously of an undirected nature (a link going from actor A to B indicating that A mentions B as a collaborator in -say- writing, should also be a link going from actor B to A), I symmetrized the matrices to turn every directed edge into an undirected one. The reciprocity level was high enough in the directed matrices (always higher than $70 \%$ ) to justify this procedure. ${ }^{6}$ This also allowed me to include non-respondents in the matrices, assuming that the links they received from respondents were in turn reciprocated. Hence, the matrices for 2008 have 147 rows and columns, whereas the matrices for 2009 have 139 rows and columns.

\section{Collaboration in Writing}

${ }^{6}$ The fact that the level of reciprocity was lower than $100 \%$ could indicate that some respondents just over-report their contacts. However, it is even more likely that some individuals just underreport their links (for various reasons, including problems remembering past contacts, or rushing through the list of attendees). I contacted a few individuals after the 2008 survey took place who had more incoming links that outgoing links in the exchange of professional advice (they were named by some respondents but they did not name those respondents as contacts). None of the individuals I contacted could say for sure that the link they failed to report did not exist, and in most cases they were able to remember the existence of the link when it was mentioned to them. At least partially, this problem brings to mind the literature on cognitive social structures, which argues that people's perceptions about their communication networks are sometimes in conflict with the real communication networks in which they act (see Corman and Scott 1994; Freeman, Roman, and Freeman 1987, among others). 
Figure 1 contains the graphic depiction of the collaboration networks in writing for individuals who participated in the 2008 and 2009 conferences, both before and after each of the conferences took place. ${ }^{7}$ The two drawings for these networks are the result of adding the collaborations that existed before the conferences and to those reported to be created as a consequence of conference attendance. This way, one can see the changes in the networks that result from conference attendance.

\section{[figure 1 about here]}

A first impression from looking at figure 1 is that the network of written collaboration among attendees to the conferences is relatively sparse, but should not be unexpected since network scholarship in Political Science is only recently developing strongly and so one would expect collaboration in writing to reflect this relative novelty. The indicators presented in Table 1 allow us to get a more comprehensive idea of how the networks are structured.

\section{[Table 1 about here]}

As it would be expected for any academic meeting, the first two networks conferences have allowed for the creation of collaborative linkages, indicated by the new edges that have been formed after the conferences took place. Additionally, results in table 1 show that the collaboration networks in writing are becoming more "integrated" in the sense that the main component in each year has gotten larger after the conference. This happens despite the fact that the number of isolated nodes (individuals with no ties to any other conference attendees) remains relatively constant. This means that the formation of new links tends to involve nodes with at least some previous history of collaboration, although this is not always the case. One should also stress that this measure of

\footnotetext{
${ }^{7}$ The figures in this article were created with Netdraw, available in UCINET (Borgatti, Everett, and Freeman 2002). A total of 36 individuals attended both conferences (meaning that only about a quarter of the attendees to the $2^{\text {nd }}$ conference had attended the $1^{\text {st }}$ conference as well).
} 
number of nodes in the main component indicates that the 2009 conference has been more succesful than the 2008 integrating scholars to the main component. The main component in the 2009 network of collaboration in writing before the conference took place already contained a higher percentage of the total number of attendees in comparison to the main component in the 2008 network after that year's conference took place. Not only is the conference doing a good job of integrating participants to the main component of collaboration, but it is also attracting more scholars who already collaborate with some of the most integrated individuals in the network.

\section{Collaboration as Informal Exchange of Professional Advice}

The second type of collaborative link involved the "informal exchange of professional advice". Figure 2 presents the networks as measured after the 2008 conference, and before and after the 2009 conference. $^{8}$

\section{[Figure 2 about here]}

It is immediately clear that the networks contained in figure 2 are denser in comparison to those in figure 1 (more links among participants exist). This should not come as a surprise since -in general- the informal exchange of professional advice with colleagues demands less time as a collaborative activity than the process of joint written efforts.

\section{[Table 2 about here]}

The descriptive elements contained in table 2 show that the advice networks are approximately three times as dense as the networks of written collaboration described in table 1. These networks have fewer isolated nodes, a much higher average per attendee of new edges (based only on the 2009 data) and bigger main components, which contain in all cases over $70 \%$ of the

\footnotetext{
${ }^{8}$ The network of informal exchange of professional advice before the 2008 network is not shown here because a coding problem occurred when online responses were transferred to matrix form. Mistakenly, mentions of links that were created before the conference were collapsed with mentions of links that were created after the conference. As a result of this, there is a valid representation of the network of exchange of professional advice post 2008 conference, but the pre-conference network contains more edges than there really existed. Hence, I only present the former.
} 
conferences participants. As before, the number of edges has also grown noticeably. The average degree of attendees was 3.35 after the 2008 conference, but it grows to more than 5 for those who participated in the 2009 conference. Overall, these results reinforce the tendency exposed in the previous section: the conferences are good vehicles for the establishment of collaborative ties and promote the integration of participants into the community of network scholars who form the core represented in the main component.

While it is important to know that the conference has promoted the establishment of collaborative links, it is far more interesting to know whether those links bridge disciplinary and subfield boundaries or whether they are created between scholars working on the same scholarly niche. The establishment of collaborative links between individuals who don't share a subfield in Political Science or -for that matter- are not both political scientists is more likely to lead to richer and more diverse approaches to the study of politics. An increase in this type of collaboration would indicate the potential of this new community of network scholars to make innovative contributions to our collective understanding as a discipline of how political processes work.

\section{Assessing the Effect of the Conferences in the Collaboration between Scholars from Different Disciplines or Subfields in Political Science.}

A quick look at figures 1 and 2 shows that collaboration exists beyond subfield or disciplinary boundaries (represented by the different nodal shapes included in the figures). However, without a more systematic analysis of the patterns of collaboration, it is difficult to assess how extensive are the efforts of the participants in the conferences to engage scholars from other fields or disciplines.

A good and simple way to explore this issue is through the calculation of the E-I index created by Krackhardt and Stern (1988) and available in UCINET. The index simply captures how 
much tendency to homophily ${ }^{9}$ there is in a network based on a give attribute and is calculated with the following formula:

$$
\mathrm{E}-\mathrm{I} \text { index }=\frac{E L-I L}{E L+I L}
$$

Where EL represents the number of links between nodes that don't share a given attribute or characteristic, and IL represents the number of links between nodes who share that attribute or characteristic. The range of the index goes from -1 (complete homophily, all links are between nodes who share a given characteristic) to 1 (complete heterophily, all links are between nodes who do not share a given characteristic).

One of the questions in the surveys asked the respondent to identify herself or himself as either a political scientists or not. In a second step, respondents that identified themselves as political scientists were asked to choose the main subfield in which they were active (American Politics, Public Policy/Public Administration, Comparative Politics, IR, or "other field"). The information collected through these two steps was combined to create a categorical variable with 6 possible values $(0=$ the respondent is not a political scientist, $1=$ the respondent is a Public Policy/Public Administration Scholar, $2=$ the respondent is an American Politics Scholar, etc.). The E-I index was then calculated in UCINET using this variable. Results are presented in table 3.

\section{[Table 3 about here]}

The results of calculating the E-I index in the seven networks show a tendency toward heterophily. In the case of the networks of collaboration in writing, the original pattern of linkages (before the 2008 conference) shows a negative value, although close to zero. After the 2008 conference, however, the negative value is cut almost in half, showing that -if anything- the conference has contributed to creating ties between individuals who don't share disciplines or that are not professionally active in the same subfield in Political Science. In 2009 the pattern is

\footnotetext{
${ }^{9}$ Homophily is simply the tendency of an actor to select others who are similar.
} 
repeated. Before the conference, the value of the index is still negative (although again, close to zero), but the network of collaboration in writing that results after the conference took place is more "heterophilic", as signaled by the slightly positive value of the index.

In the networks of informal exchange of professional advice, the same progression can be observed, although the analysis must be confined to the 2009 networks since the "network before the 2008 conference" is not available. Before the 2009 conference, the value of the index is well above zero, showing that the exchange of professional advice among attendees to the conference is already diverse, but the value continues to grow after the conference. Overall, these results show that new collaborative links created at the Political Networks conferences tend to diversify professional collaboration by extending beyond the confines of different disciplines or subfields in Political Science; the ability to promote multidisciplinary and cross-field work seems to be one of the trademarks of the conferences -at least in their initial editions.

A few years ago, Grant (2005) questioned the idea of political scientists sitting at "different tables" proposed by Almond (1988), who claimed that there is a double division (ideological and methodological) that structure relationships inside the discipline. Grant conducted an analysis of the pattern of membership to APSA sections, and concluded that political scientists grouped around common subjects of inquiry, rather than ideological or methodological views. The new connections that emerge among attendees to the networks conference and increase the heterogeneity of collaborative patterns provide support for this optimistic view that has scholars interacting with each other in potentially productive ways.

Of course, one should not miss the important point that there are niches among network scholars; after all, the majority of collaborative links still occur inside subfields in Political Science-that much can be concluded from a simple look at the pictures of the network of collaboration offered in this article. However, the boundaries of these niches are likely to be progressively blurred 
as more and more scholars step out of the familiarity of their own fields to engage in collaboration with others as indicated by the changes in the E-I indexes.

Additionally, one should keep in mind that there are many potential benefits from the establishment of scholarly collaborative links among members of different disciplines represented at the conferences. Interdisciplinary collaboration can lead to better informed theories and improved methodological approaches to study phenomena that exceed disciplinary limits, which in turn should benefit scholars in a number of ways, from getting access to wider audiences, to maybe increasing the likelihood of having their work published in the main journals of their disciplines, as it seems to be the case with at least one top journal in Political Science (see Sigelman 2009).

\section{Conclusion}

This article presents a simple description of how scholars in Political Science and other disciplines who attended the two first Political Networks conferences in 2008 and 2009 collaborate with each other both in writing and by informally exchanging professional advice. Some of the findings exposed above seem to indicate that in fact a new community of scholars is forming which is diverse and potentially innovative in its approach to the study of political phenomena. These findings include the growing number of collaborative links among attendees to the conferences, the decaying number of isolated individuals, and the tendency of the networks of collaboration to reach higher levels of integration by including more nodes in their larger components.

However, perhaps the most important finding is that networks of collaboration seem to become more "heterophilic" overtime, indicating that collaboration is developing across subfields of political science and also across whole disciplinary boundaries. Political scientists attending the conference do not seem to benefit only from their interactions with other political scientists, but also from their collaboration with sociologists, computer scientists, philosophers, Law scholars, social psychologists, and statisticians. In this sense the conferences may be a good vehicle to achieve 
the main goal of the new Political Networks section of the American Political Science Association, which is to promote "... a better understanding of network theorizing and analysis across political science and to connect the study of networks in political science to other disciplines as well.,"10

There are now many more political scientists interested in the study of political phenomena from a network perspective than there were a few years ago, but it is still too early to know with any degree of certainty whether network studies in our discipline are here to stay or not. However, one thing is clear: the Political Networks conferences seem to be contributing to the creation of a strong scholarly community from which innovative research agendas are likely to sprout in the future. This can only add to the strengthening of network studies in contemporaneous American Political Science.

\section{References}

Almond, Gabriel. 1988. "Separate Tables: Schools and Sects in Political Science.” PS: Political Science and Politics 21(4): 828-842.

Borgatti, S.P., Everett, M.G. and Freeman, L.C. 2002. Ucinet for Windows: Software for Social Network Analysis. Harvard, MA: Analytic Technologies.

Corman, Steven R., and Craig R. Scott. 1994. "Perceived Networks, Activity, Foci, and Observable Communication in Social Collectives.” Communication Theory 4: 171-190.

Freeman, Linton C., A. Kimball Romney, and Sue C. Freeman. 1987. “Cognitive Structure and Informant Accuracy." American Anthropologist 89: 311-325.

Garand, James C. and Michael W. Giles. 2003. "Journals in the Discipline: A Report on a New Survey of American Political Scientists.” PS: Political Science \& Politics 36(2): 293-308.

Grant, J. Tobin. 2005. "What Divides Us? The Image and Organization of Political Science.” PS: Political Science \&o Politics 38(3): 379-386.

\footnotetext{
${ }^{10}$ Full statement available at https://www.apsanet.org/content_64174.cfm
} 
Krackhardt, David and Robert Stern. 1988. “Informal Networks and Organizational Crises: An Experimental Simulation.” Social Psychology Quarterly 51:123-140.

Sigelman, Lee. 2009. “Are Two (or Three or Four... or Nine) Heads Better than One?

Collaboration, Multidisciplinarity, and Publishability." PS: Political Science \& Politics 42(3): 507512. 


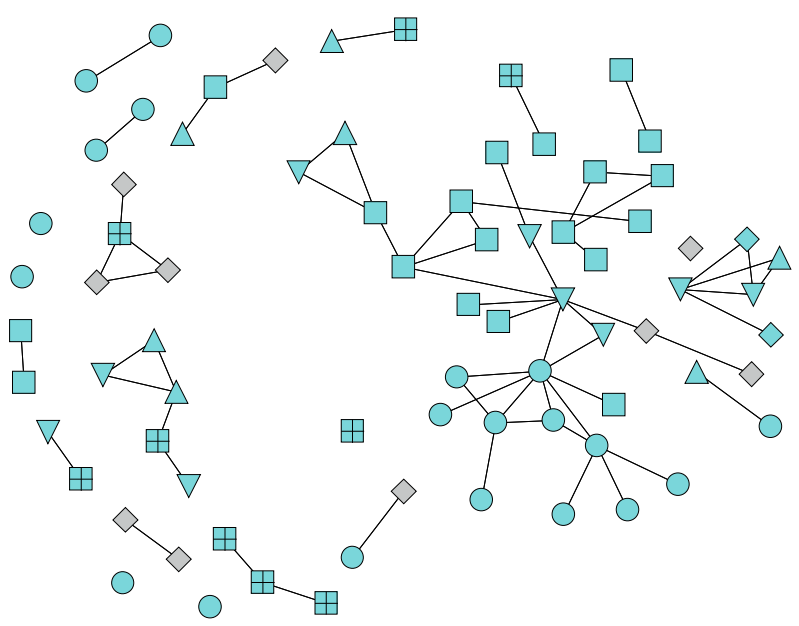

Written Collaboration Before 2008 Conference

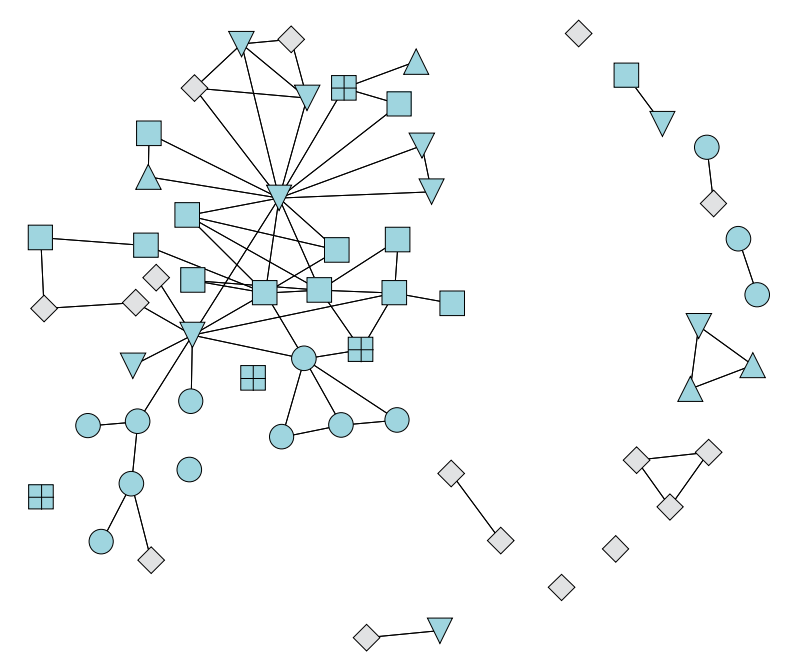

Written Collaboration Before 2009 Conference

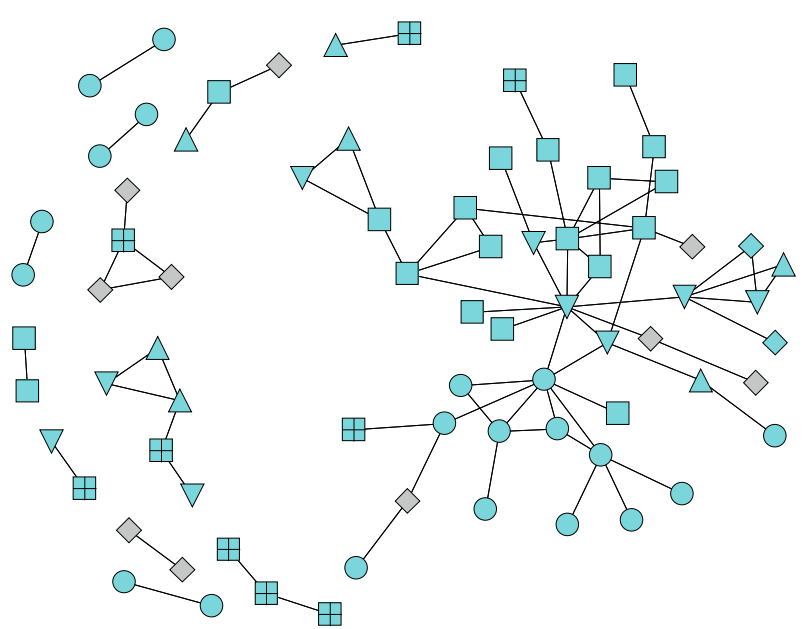

Written Collaboration After 2008 Conference

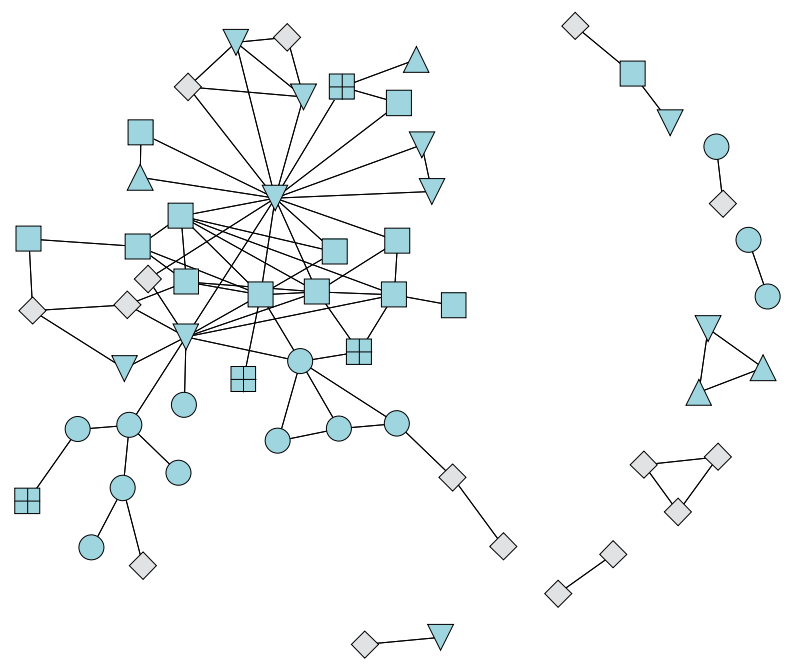

Written Collaboration After 2009 Conference

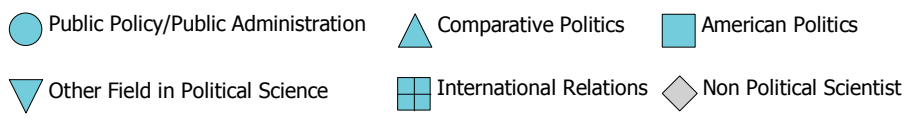

Figure 1. Networks of Written Collaboration 


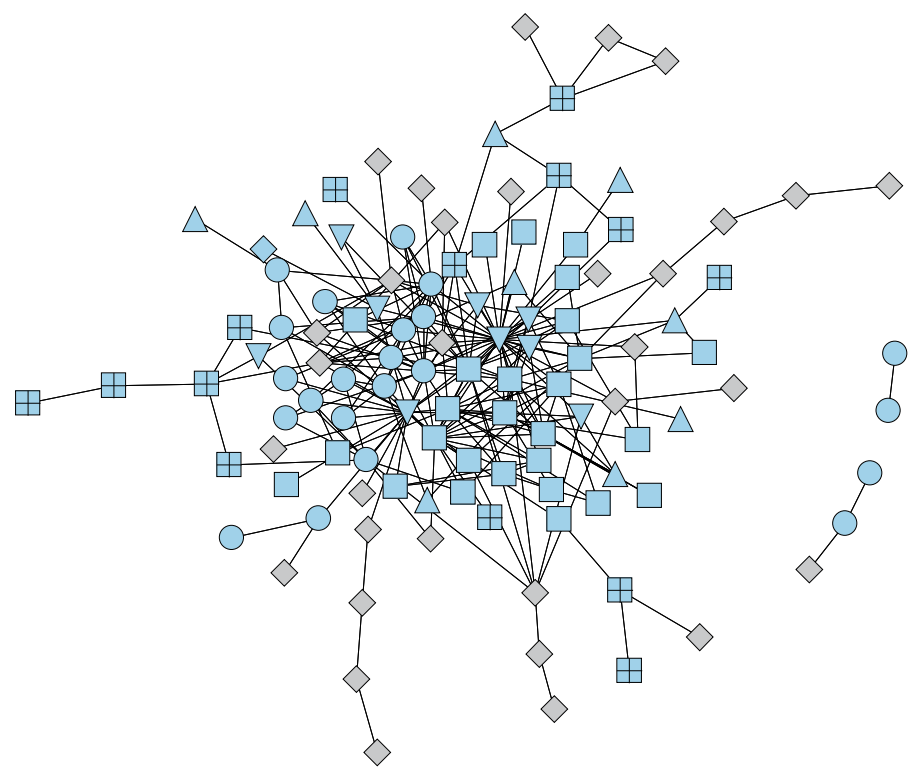

Exchange of Professional Advice After 2008 Conference

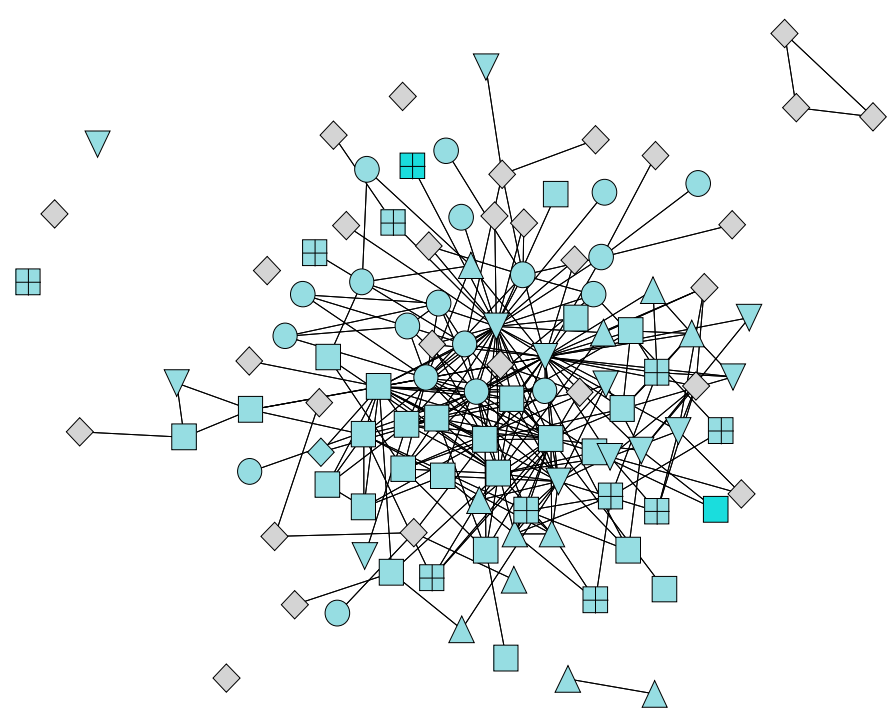

Exchange of Professional Advice Before 2009 Conference

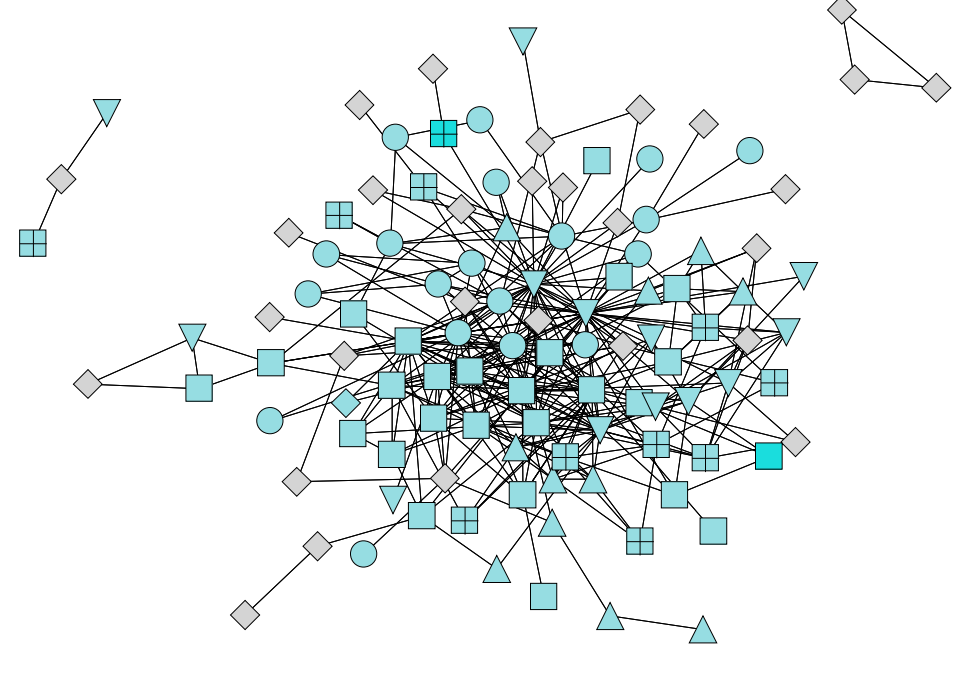

Exchange of Professional Advice After 2009 Conference

\footnotetext{
$\bigcirc$ Public Policy/Public Administration $\triangle$ Comparative Politics $\square$ American Politics

$\nabla$ Other Field in Political Science $\quad \square$ International Relations $\diamond$ Non Political Scientist
}

Figure 2. Networks of Exchange of Professional Advice 
Table 1. Networks of Collaboration in Writing

\begin{tabular}{|c|c|c|c|c|}
\hline & \multicolumn{4}{|c|}{ Collaboration in Writing } \\
\hline & $\begin{array}{c}\text { Before } \\
2008 \\
\text { conf. } \\
\end{array}$ & $\begin{array}{c}\text { After } \\
2008 \\
\text { conf. }\end{array}$ & $\begin{array}{c}\text { Before } \\
2009 \\
\text { conf. }\end{array}$ & $\begin{array}{l}\text { After } \\
2009 \\
\text { conf. }\end{array}$ \\
\hline \# of Nodes & 147 & 147 & 139 & 139 \\
\hline $\begin{array}{l}\text { New Edges } \\
\text { (average per attendee) }\end{array}$ & - & $\begin{array}{c}30 \\
(0.20)\end{array}$ & - & $\begin{array}{c}30 \\
(0.22)\end{array}$ \\
\hline $\begin{array}{l}\text { Nodes in Main Component ( } \% \text { of } \\
\text { total attendees) }\end{array}$ & $\begin{array}{c}26 \\
(17.69 \%)\end{array}$ & $\begin{array}{c}39 \\
(26.53 \%)\end{array}$ & $\begin{array}{c}42 \\
(30.22 \%)\end{array}$ & $\begin{array}{c}47 \\
(33.81 \%)\end{array}$ \\
\hline Isolate nodes ${ }^{11}(\%$ of total attendees) & $\begin{array}{c}71 \\
(51.70 \%)\end{array}$ & $\begin{array}{c}71 \\
(51.70 \%)\end{array}$ & $\begin{array}{c}83 \\
(59.71 \%)\end{array}$ & $\begin{array}{c}76 \\
(54.68 \%)\end{array}$ \\
\hline \# of Edges (directed) & 128 & 158 & 152 & 182 \\
\hline Average Degree (\# Edges/\# Nodes) & 0.87 & 1.07 & 1.09 & 1.31 \\
\hline Density $^{12}$ & 0.0060 & 0.0073 & 0.0079 & 0.0094 \\
\hline
\end{tabular}

${ }^{11}$ Isolates are not showed in the pictures to preserve readability.

${ }^{12}$ Density is measured simply as $\frac{\text { \# of edges }}{\text { \# of nodes } * \text { \# of nodes }-1)}$ 
Table 2. Networks of Exchange of Professional Advice.

\begin{tabular}{lccc} 
& \multicolumn{3}{c}{ Exchange of Professional Advice } \\
\cline { 2 - 4 } & $\begin{array}{c}\text { After 2008 } \\
\text { conf. }\end{array}$ & $\begin{array}{c}\text { Before } \\
\text { 2009 conf. }\end{array}$ & $\begin{array}{c}\text { After 2009 } \\
\text { conf. }\end{array}$ \\
\hline \# of Nodes & 147 & 139 & 139 \\
& - & - & 156 \\
$\begin{array}{l}\text { New Edges } \\
\text { (average per attendee) }\end{array}$ & 108 & 99 & $1.12)$ \\
$\begin{array}{l}\text { Nodes in Main Component (\% of } \\
\text { total attendees) }\end{array}$ & $(73.47 \%)$ & $(71.22 \%)$ & $(74.82 \%)$ \\
Isolate nodes & & & 104 \\
& 34 & 35 & 29 \\
& $(23.13 \%)$ & $(25.18 \%)$ & $(20.86 \%)$ \\
\# of Edges (directed) & 492 & 542 & 698 \\
Average Degree (\# Edges/\# Nodes) & 3.35 & 3.90 & 5.02 \\
\hline
\end{tabular}

${ }^{13}$ Isolates are not showed in the pictures to preserve readability. 
Table 3. Homophily in the Networks of Professional Collaboration.

\begin{tabular}{lcccc} 
& \multicolumn{2}{c}{2008 (E-I Index) } & \multicolumn{2}{c}{2009 (E-I Index) } \\
\cline { 2 - 5 } & $\begin{array}{c}\text { Before the } \\
\text { conference }\end{array}$ & $\begin{array}{c}\text { After the } \\
\text { conference }\end{array}$ & $\begin{array}{c}\text { Before the } \\
\text { conference }\end{array}$ & $\begin{array}{c}\text { After the } \\
\text { conference }\end{array}$ \\
\hline $\begin{array}{l}\text { Informal } \\
\text { Exchange of } \\
\text { Professional } \\
\text { Advice }\end{array}$ & - & 0.15 & 0.20 & 0.23 \\
& & & & \\
$\begin{array}{l}\text { Collaboration in } \\
\text { Writing }\end{array}$ & -0.06 & -0.03 & -0.03 & 0.01 \\
\hline
\end{tabular}

